\title{
A numerical study of the ex-ROFI of the Colorado River
}

\author{
N. Carbajal ${ }^{a}$, A. Souza ${ }^{b}$, R. Durazo ${ }^{\text {c }}$ \\ ${ }^{a}$ Institute for Marine and Atmospheric Research, University of Utrecht, Princetonplein 5, 3584 CC Utrecht, The Netherlands \\ ${ }^{\mathrm{b}}$ School of Ocean Sciences, University of Wales, Cardiff, UK \\ ' Facultad de Ciencias Marinas, Universidad de Baja California, Ensenada, Mexico
}

Received 21 September 1995; revised 29 March 1996; accepted 28 May 1996

\begin{abstract}
The freshwater discharge of the Colorado River into the Gulf of California has been reduced to negligible quantities since the construction of the Hoover Dam in 1935. These radical anthropogenic changes in the hydrography of the Colorado River Delta had striking repercussions on both physical and biolugical processes. Using historical river discharge data, the changes in the flow dynamics and hydrographic patterns before and after the drastic freshwater reduction are studied numerically, using a three-dimensional nonlinear shelf model. The results are applied to assess the environmental impact of the reduction of river discharge on the area. Satellite imagery is also used to compare our results with observed fronts. (C) 1997 Elsevier Science B.V.
\end{abstract}

Keywords: numerical modelling; freshwater; tidal currents; satelite imagery; anthropogenic changes

\section{Introduction}

The river discharge in the probably once majestic area of the Colorado River Delta, has been reduced to occasional volumes of water. Possible extreme anthropogenic changes generated in the dynamics, and in general in the ecological system of the region have not yet been studied. The principal motivation of this work is to gain a first insight into the principal characteristics of the flow and hydrographic structures in the Colorado Delta at times when the river discharge was high and continuous, i.e. at the beginning of this century, and to compare them with present-day conditions. Consequences of the river discharge reduction on physical processes in the rest of the Gulf of California are also investigated. The changes in the area of the Colorado River mouth have been dramatic. A tidal bore of 10 feet $(\sim 3 \mathrm{~m})$ was observed during spring tides at the beginning of this century (Sykes, 1937). This bore was reported to capsize small boats that navigated the river including the loss of human lives. At present, the river is no longer used for navigation. The bore is still a feature of the region but observers report maximum heights of about $\sim 1 \mathrm{~m}$.

Physical processes which take place nowadays indicate that the Colorado River Delta has signiticant influence on the rest of the Gulf. For example, estimates of tidal energy budgets reveal that rates of dissipation of tidal energy are very strong in this region. Carbajal (1993) showed that the total energy dissipated $\left(\mathrm{M}_{2}\right.$ tide) in the area of the Colorado River Delta is of the same order as that in the rest of the Gulf. This energy dissipation causes a westward shift of the amphidromic point situated in the central Gulf. Therefore, the process of dissipation of tidal 


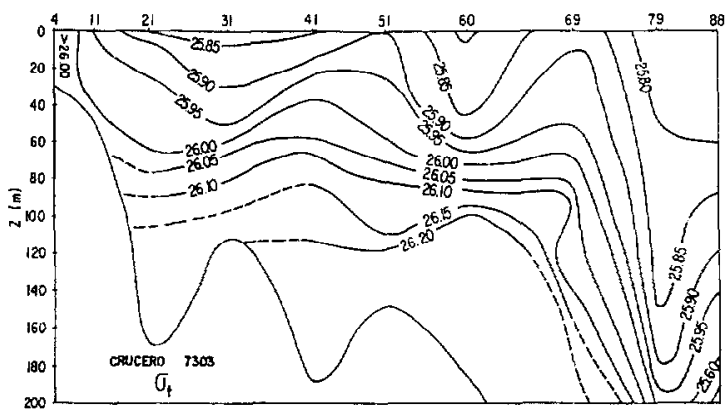

Fig. 1. Vertical distribution of density $\sigma_{t}$. Transect between the area of the Colorado Delta and island Tiburon. Taken from Alvarez-Borrego and Schwartzlose (1979).

energy which occurs in the delta, markedly influences the tidal flow in the whole Gulf. Another example is the saline water mass formed in the northernmost part of the Gulf during the summer (Northern Gulf Water, NGW) which sinks in winter and moves into the central Gulf where it mixes with Intermediate Pacific Water (IPW). Based on measurements carried out between the Colorado Delta and island Tiburon, Alvarez-Borrego and Schwartzlose (1979) describe this process in detail (see Fig. 1). The result of this mixing is known as Central Gulf Water (CGW) (Bray, 1988a; Simpson et al., 1994). It is of relevant importance to explore whether the presence of freshwater in the upper layers of the Colorado River Delta could significantly modify the two above-mentioned cases and perhaps other processes as well.

The Colorado River originates in the Rocky Mountains, USA, its length being slightly more than $2200 \mathrm{~km}$. It flows through seven states within the US before entering Mexican territory and terminating in the Gulf of California (Fig. 2). The river has experienced substantial declines in discharge throughout this century due to damming and irrigation withdrawal (Baba et al, 1991). Between 1910-1920, the mean discharge was of the order of $21.4 \times 10^{9} \mathrm{~m}^{3} / \mathrm{yr}$ (see Fig. 3). After 1920, the discharge decreased dramatically owing to the extensive irrigation of the newly cultivated fields along the river. In 1934, after the completion and filling up of the Hoover Dam, the discharge decreased drastically to $1.8 \times 10^{9} \mathrm{~m}^{3} / \mathrm{yr}$ showing a slight recovery between 1940 and 1952 . Following completion of the Glen Canyon Dam in

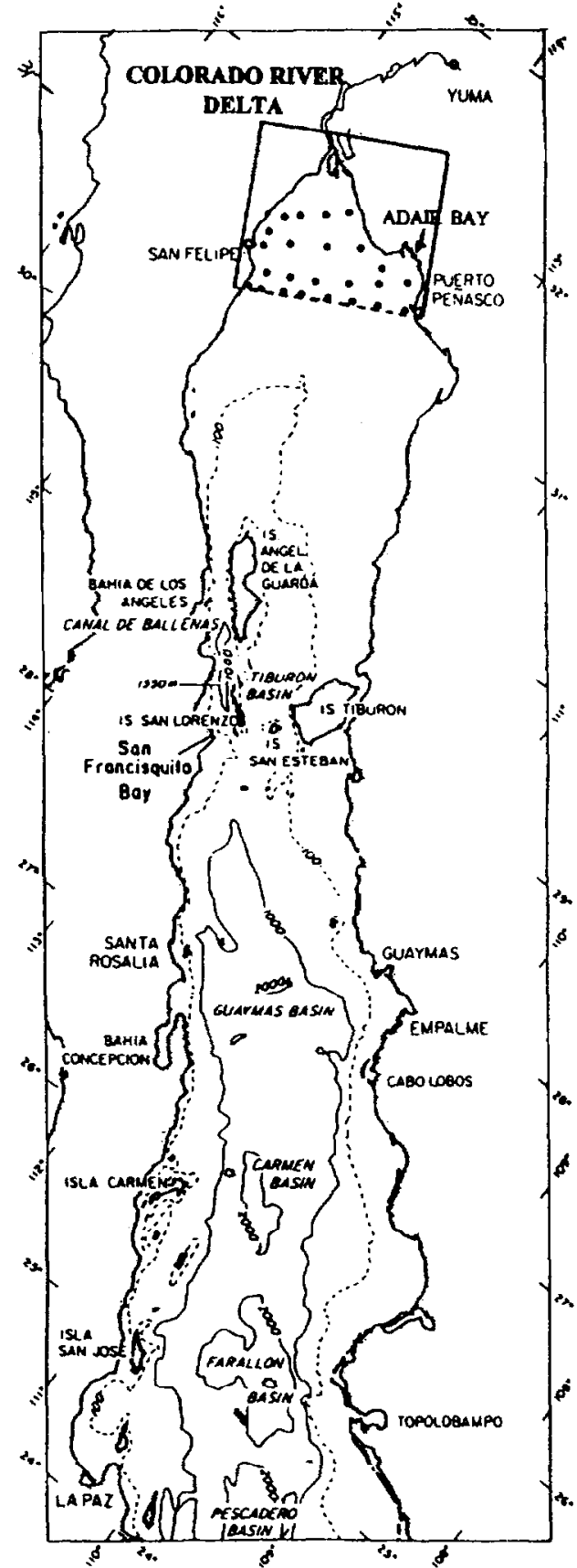

Fig. 2. Geography and some bathymetric features of the Gulf of California. The rectangle denotes the studied region of the Colorado River Delta. The small dots indicate the position of the availablc hydrographic data. 


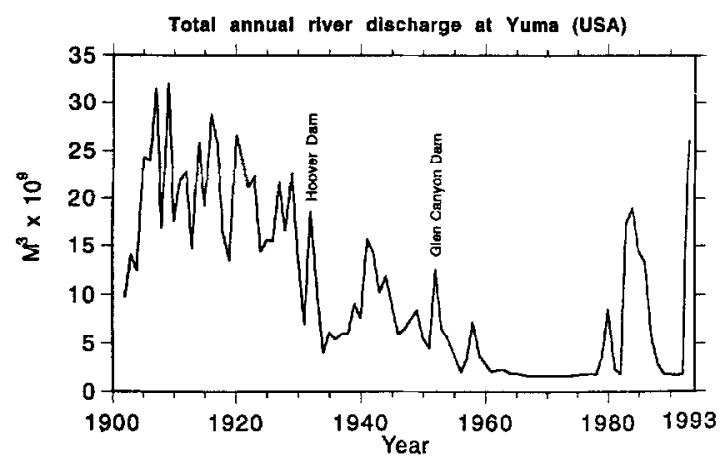

Fig. 3. Total annual river discharge of the Colorado River.

1952 , the freshwater flow to the ocean decreased to $0.8 \times 10^{9} \mathrm{~m}^{3} / \mathrm{yr}$. This flow represented only $4 \%$ of the original discharge registered between 1910-1920. At present, the Mexico-US treaty establishes that the US must provide, from "any source", an annual quota of $1.8 \times 10^{9} \mathrm{~m}^{3}$. The discharge established by the treaty does not reach the upper Gulf of California however, because water is used for irrigation in Mexican territory or is lost by filtration before entering the ocean. The only periods when a considerable amount of freshwater is contributed to the Gulf is during strong precipitation events (e.g., 1980, 1985 , 1993), through small tributaries and through an increase in the discharge from the dams upstream.

There are no hydrographic observations documented for the Colorado River Delta prior to 1970. Even after 1970, observations have been sporadic and non-systematic as to establishing the relationship between the amount of freshwater discharged and the changing conditions in temperature and salinity (Alvarez-Borrego et al., 1975). The reason for this lack of observations is that the area is a desert and extremely inaccessable. Daytime air temperature can reach $50^{\circ} \mathrm{C}$ during the summer, dropping to relatively low temperatures at night. Indeed, it is in this region of the Gulf of California where mean monthly air temperature shows the greatest difference. It changes from $\sim 11.4$ in January to $\sim 29.7$ in August (Roden and Emilsson, 1979). The area also experiences high evaporative rates. Values of more than $3 \mathrm{~m} / \mathrm{yr}$ have been reported (Bray, 1988a). The total annual precipitation is in the order of $75 \mathrm{~mm}$. This imbalance leads to the formation of high saline water.
Despite the fact that paved roads have been built during the last decade, the large tidal range $(7-10 \mathrm{~m})$ which generates tidal currents of up to $3 \mathrm{~m} / \mathrm{s}$ along the channels and the highly mobile sediment, have prevented researchers from deploying moored instruments there. Those who have attempted to deploy wave recorders, for example, have completely lost track of the systems after severe storms. The area is thus dynamically very attractive as well as extremely challenging.

There are only a few works on the baroclinic circulation in the Gulf of California where the area of the Colorado River Delta is considered. In a study on the thermohaline structure in the Gulf. Bray (1988a,b) found a dominant cyclonic baroclinic circulation in the Colorado Delta. Numerical simulations of the baroclinic circulation in the Gulf show that in the area of the Colorado Delta the flow has a decisively cyclonic character in summer (Carbajal, 1993). In winter a weak anticyclonic circulation takes place. A tidal mixing front during the summer has been described for the upper Gulf in relation to the $h / u^{3}$ parameter ( $h$ is the water depth and $u$ is the amplitude of tidal currents) (Argote et al., 1985; Durazo, 1989). The front, located approximately at the $40 \mathrm{~m}$ isobath, is of the bottom type (Hill and Simpson, 1989) and is thus not commonly detected in infrared imagery. However, due to the high reflectivity of resuspended sediment, the different conditions between shallow and deep waters may be observed when sensors with a wavelength of $0.5-0.6$ $\mathrm{mm}$ are used. Fig. 14, for example, depicts a Landsat MSS band 1 image for the region of the Colorado Delta. A high reflectivity area, possibly reflecting resuspended sediments is observed over the shallow shelf.

Despite the sharp decrease of the Colorado River runoffs, there seems to be no effect on the mass accumulation rates of terrigenous sediment over the basins of the upper Gulf of California. From core analysis, Baba et al. (1991) found that an apparent stability in the mass accumulation rate of sediments occurs because these are being carried from sources other than the Colorado River. Neglecting the effect of small tributaries and eolic transport, they suggested that resuspension by tidal currents over the shallow shelf of the northern Gulf, supplies sediments to the deeper slopes and basins. 
The region of the Colorado Delta is of remarkable importance to the ecology of several land and marine organisms. Large numbers of seabirds breed over the flat islands of Montagne and isla Pelicano located at the river mouth. Shrimp trawling is one of the main commercial activities in the Gulf of California; the shallow areas near the mouth are essential for shrimp larvae survival. Furthermore, endemic and endangered species are found in the upper Gulf, the white sea-bass Toloaba Macdonaldi and the sea marnal Phocoena sinus among others. Because of its ecological importance and in order to prevent any further damage to this pristine region, the Mexican government formulated an Act in 1993 establishing the region north of a line joining San Felipe to Santa Clara, as a reserve of the biosphere (Sedesol, 1993) permitting no further fishing or hunting.

\section{Area of study and applied model}

In the Colorado River Delta patterns of well defined front-like structures of temperature, salinity and tidal flow are observed. A criterium for the selection of the case study area was then to include those zones where these patterns are detected. In Fig. 2 the geography and some bathymetric characteristics of the Gulf of California are given. The location of the model region and the position of hydrographic stations of avalaible data are also indicated. The region studied consists of a rectangular area of $130 \mathrm{~km}$ in the along-delta and $137 \mathrm{~km}$ in the crossdelta direction. Principal features are the islands Montague, Gore and Pelicano in the northernmost part and the Bay of Adair on the east (Fig. 4). The main watercourse of the Colorado River divides into two streams on either side of island Montague. Fig. 4(top) displays the bathymetry used in the calculations. The northern half is very shallow with a minimum depth of $2 \mathrm{~m}$ and a maximum of $30 \mathrm{~m}$. The southern half is characterized by topographic gradients around the Wagner Basin where a maximum depth of $\sim 130 \mathrm{~m}$ is found. The applied grid spacing was $1 \mathrm{~km}$. Since satellite imagery shows large concentrations of suspended sediment, we are aware of the possibility of a changing sea bottom morphology. However, we think that with this grid size the principal topographic features are well resolved.

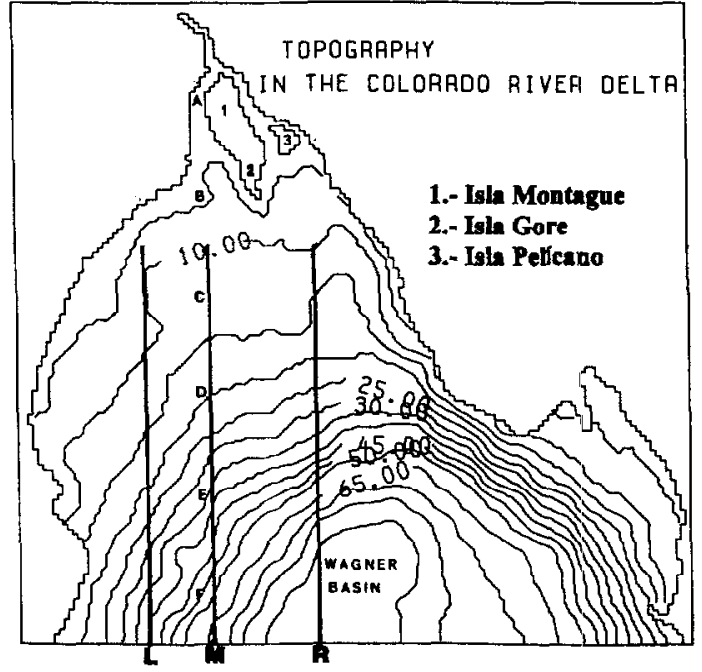

Fig. 4. Bathymetry (m) of the modelled region.

A semi-implicit three-dimensional non-linear shelf model was applied in the calculations Backhaus (1985). The model has been adapted succesfully to a series of studies of barotropic, baroclinic, winddriven and tidal circulation in regions like the North Sea (Hainbucher et al., 1987), the South China Sea (Pohlmann, 1985), Strait of Georgia (Crean et al., 1988) and the Gulf of California (Carbajal, 1993). All model characteristics have recently been described in detail by Stronach et al. (1993). Six levels at the depths of $10,20,30,50,100$ and $131 \mathrm{~m}$ (maximum depth) were implemented in the model. The friction coefficient was variable and a function of the depth. We used a formula after Baumert and Radach (1992)

$r=\left\{\frac{\kappa}{\ln \left[E\left(1+\frac{1}{p}\right)^{1+p}\right]}\right\}^{2}$

where $\mathrm{\kappa}=0.4$ denotes the Karman constant, $p=K_{s}$ $/ h$ is a parameter with $K_{s}=1.5$ (linear size of the roughness) and $h$ the depth, $E=11.02$. With these values, the friction coefficient varied between $r \sim$ 0.003 and $r \sim 0.01$. In the northern part of the Gulf of California semidiurnal tides are dominant. Among these, the $M_{2}$ tide is the most important. Amplitudes and phases of this tidal constituent necessary to force 
the region at the open boundary, were taken from observations at Puerto Peñasco and completed with results of numerical modelling of tides in the whole Gulf of California (Carbajal, 1993). At the surface, a heat input of $100 \mathrm{w} / \mathrm{m}^{2}$ was selected in all calculations which corresponds to a late summer mean day value (Castro et al., 1994). In simulations where a river discharge was considered, an input of freshwater of $2000 \mathrm{~m}^{3} / \mathrm{s}$ was forcing the region at the northernmost wet point. This value represents a situation of high river discharge. The quantity of hydrographic data measured in this region was scarce and insufficient to fill all grid points of the model region. Data of only 24 stations measured from 18-22th September of 1971 were available. However, the stations are well distributed in the Colorado Delta as shown in Fig. 2.

\section{Results}

In order to study present (without river runoff) and past (with river runoff) flow conditions in the Colorado River Delta, several baroclinic calculations were carried out. In order to accomplish this, temperature and salinity fields, obtained from the arrangement and interpolation of available hydrographic data, were initially adjusted to topographic and gengraphic features through a short $(10 \mathrm{~d})$ prognostic calculation. In this run, only horizontal density gradients and, of course, a heat input of $100 \mathrm{w} / \mathrm{m}^{2}$ at the surface were forcing the system, i.e. neither the $M_{2}$ tide nor river discharge were included. The resulting temperature and salinity fields were then used as initial conditions in the following two calculations.

\subsection{Baroclinc simulation of the $M_{2}$ tide}

To investigate the propagation of semidiurnal tidal waves in the Colorado River Delta, a prognostic simulation was carried out with only the $M_{2}$ tide forcing the region at the open boundary. It was iterated for 25 periods $(\approx 12.9 \mathrm{~d})$. The calculated amplitudes and phases are given in Fig. 5. Amplitudes increased from about $1.5 \mathrm{~m}$ at the open boundary to $2.2 \mathrm{~m}$ on the southern side of island Montague. From this area, the amplitudes on both sides

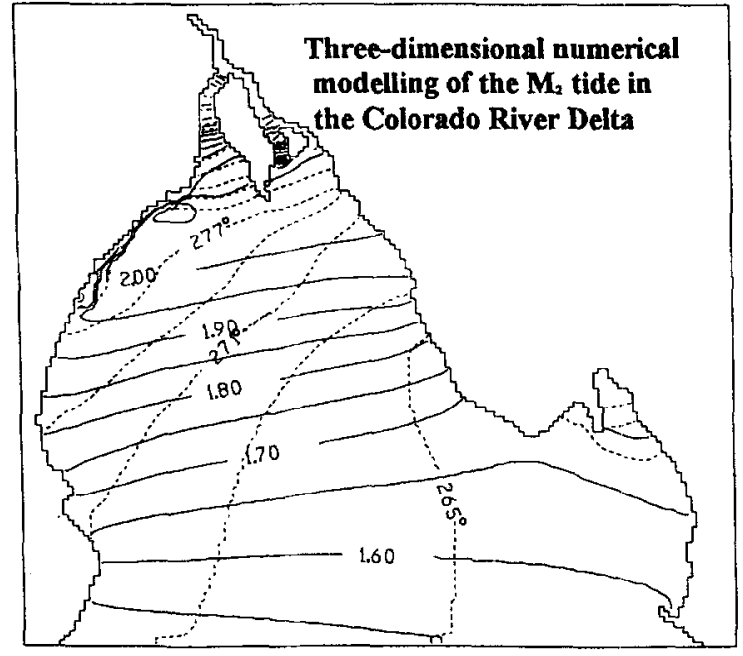

Fig. 5. Amplitude (continuous lines) in $\mathrm{m}$ and Phase (broken lines) in degrees of the $M_{2}$ tide in the Colorado River Delta.

of the island decayed rapidly until a minimum of $\sim 0.3 \mathrm{~m}$ at the point where the watercourse of the Colorado River divides into two streams. To our knowledge, no data on amplitudes and phases in this area has been published. However, observers of expeditions organized by the Facultad de Ciencias Marinas (Universidad de Baja California, Mexico) mentioned amplitudes of a few decimetres in the northernmost part of the Colorado Delta (pers. commun.). Phase line changed from a general meridional in the southern region to a zonal course in the narrow region in the north. The observed amplitude $(1.65 \mathrm{~m})$ and phase $\left(268^{\circ}\right)$ at San Felipe agreed quite well with the calculated $\left(1.68 \mathrm{~m}, 272^{\circ}\right)$. Large phase changes occured on both sides of island Montague. It is probably in this region of large amplitude and phase gradients where the previously mentioned bore might have occured.

\subsection{Simulation of the Colorado river ROFI}

A new prognostic calculation was performed with the initial fields of temperature and salinity. This time, the $M_{2}$ tide at the open boundary and a river discharge of $2000 \mathrm{~m} / \mathrm{s}$ were forcing the system. Partial results showed that the region of freshwater influence (ROFI) gradually began to grow. The shal- 
lowness of the area and the strong tidal currents led to intense tidal stirring. It inhibited stratification and avoided the creation of coastal currents which could have accelerated the expansion of freshwater southwards. Indeed, the ROFI advanced tortuously with a mean velocity of $\sim 1.1 \mathrm{~km} /$ period or equivalently $\sim 0.025 \mathrm{~m} / \mathrm{s}$. Although a nearly stationary state was reached after $80 \mathrm{M}_{2}$ periods $(41.4 \mathrm{~d})$, the calculation was continued until $100 \mathrm{M}_{2}$ periods $(51.7 \mathrm{~d})$.

One of the most important purposes of unr work was to investigate the differences in salinity distributions between situations with and without river discharge. Horizontal salinity distributions representing actual conditions (initial data) and of the salinity after $100 M_{2}$ periods representing the ROFI situation were compared. The salinity patterns were radically different. In Fig. 6a, surface salinity values of present conditions were high in the whole delta and varied only between $\sim 35$ and 37 psu. However, a front extending in the east-west direction could be distinguished. This front coincided with the topographic gradients which is an indication that evaporation leads to higher salinities in the shallower areas of the Colorado Delta. After $100 M_{2}$ periods (Fig. $6 \mathrm{~b})$, the influence of freshwater in the surface layer $(0-10 \mathrm{~m})$ reached predominantly the northern half of the delta, where salinities changed from 3-35 psu. However, the river runoff also influenced the rest of the simulated area, since the salinity values were slightly lower than the initial data. Salinity gradients are mostly oriented in the along delta direction and show a regular pattern. The influence of freshwater is clearly larger on the eastern side. In the third layer $(20-30 \mathrm{~m})$, the effect of low saline water is detected only in a small area (Fig. 7b). Observe that, compared with the surface layer, the isohaline of 35 psu is situated markedly northward. In the same depth range, the salinity structure of the initial data were similar to that of the surface layer (Fig. 7a). It proved that vertical variations of salinity were small. We have completed the description of the region of freshwater influence with three transects displayed in Fig. 8. The position of the transects is given in Fig. 4. In the vertical, the effect of low salinity water extended until a depth of $\approx 30 \mathrm{~m}$. Since water depths are shallower on the western side of the Colorado Delta and the tidal flow was very strong (Fig. 13), the water column was completely mixed.
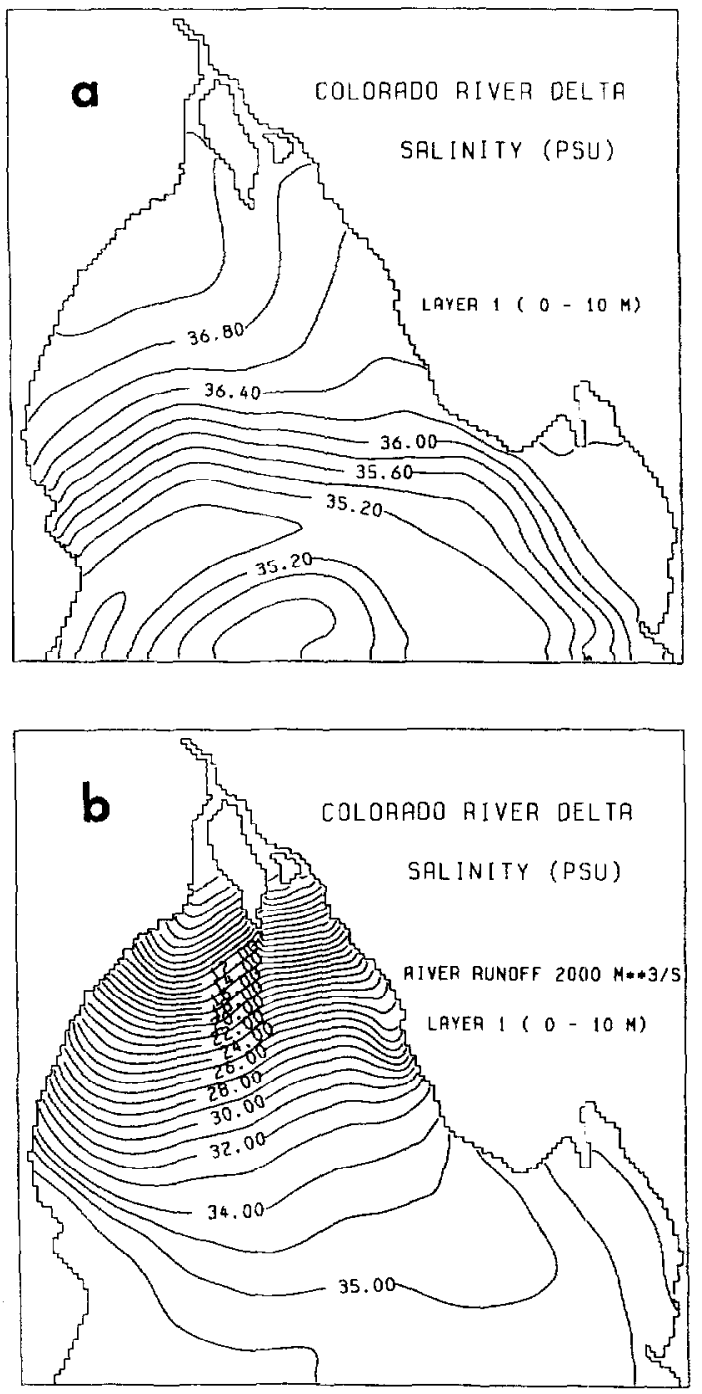

Fig. 6. Sca surface salinity in psu. (a) Salinity at present conditions. (b) Salinity distribution after $100 M_{2}$ periods with the consideration of a constant discharge of freshwater of $2000 \mathrm{~m}^{3} / \mathrm{s}$.

This is illustrated in the transect L. Conversely, Transects $M$ and $R$, located eastward, showed that the input of freshwater contributed significantly to stratification. Along the transect $R$ and in general on the eastern side of the Colorado Delta, vertical changes of salinity were large. In this deeper area, bottom friction effects were not powerful enough to mix the water column.

Since our main interest lay in the study of fresh- 
water influence, only some important temperature features are discussed. Although the sca surface of the zone undergoes a great change of temperature from $\sim 12^{\circ} \mathrm{C}$ in winter to $\sim 31^{\circ} \mathrm{C}$ in summer (Roden and Emilsson, 1979), variations in space seem to be less intense. Horizontal distributions of sea surface temperature with and without river runoff are shown in Fig. 9. The structures were similar to those of the
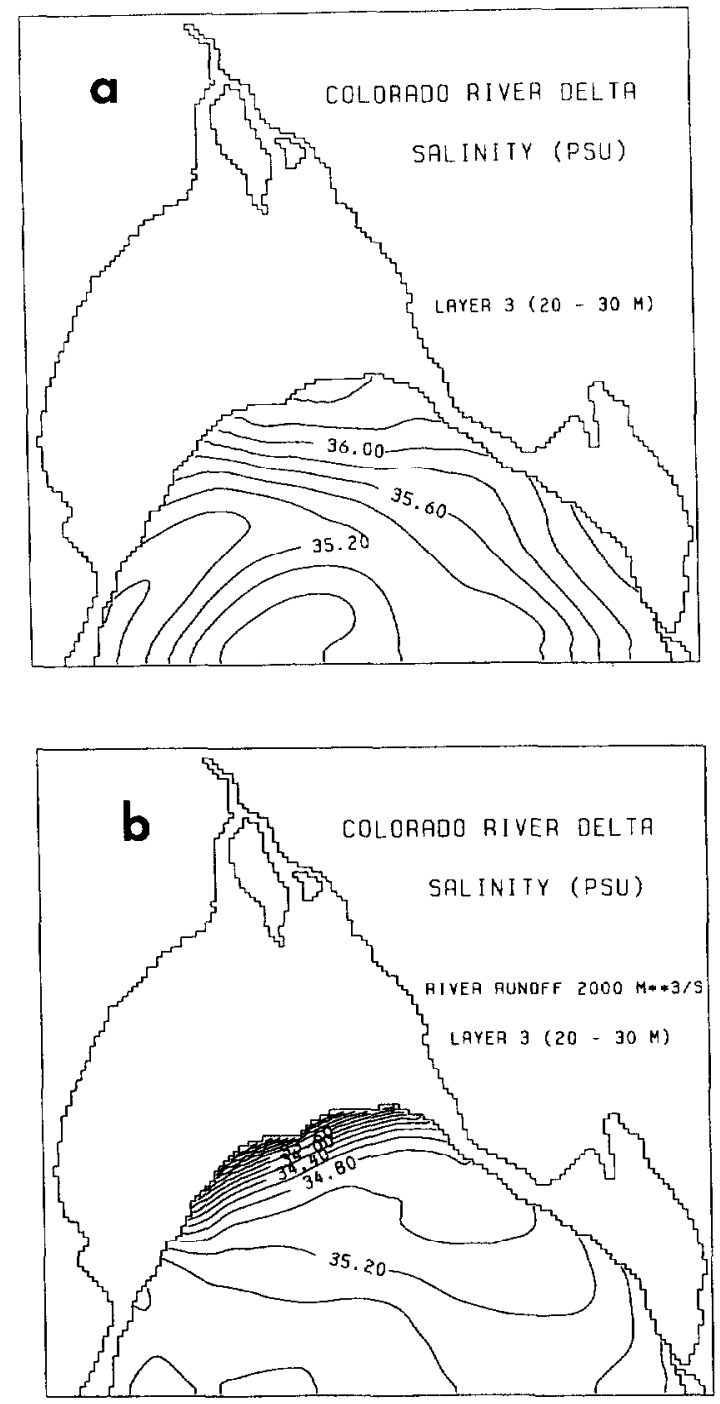

Fig. 7. Salinity (psu) in the third layer $(20-30 \mathrm{~m}$ ). (a) Salinity at present conditions. (b) Salinity distribution after $100 M_{2}$ periods with the consideration of a constant discharge of freshwater of $2000 \mathrm{~m}^{3} / \mathrm{s}$.
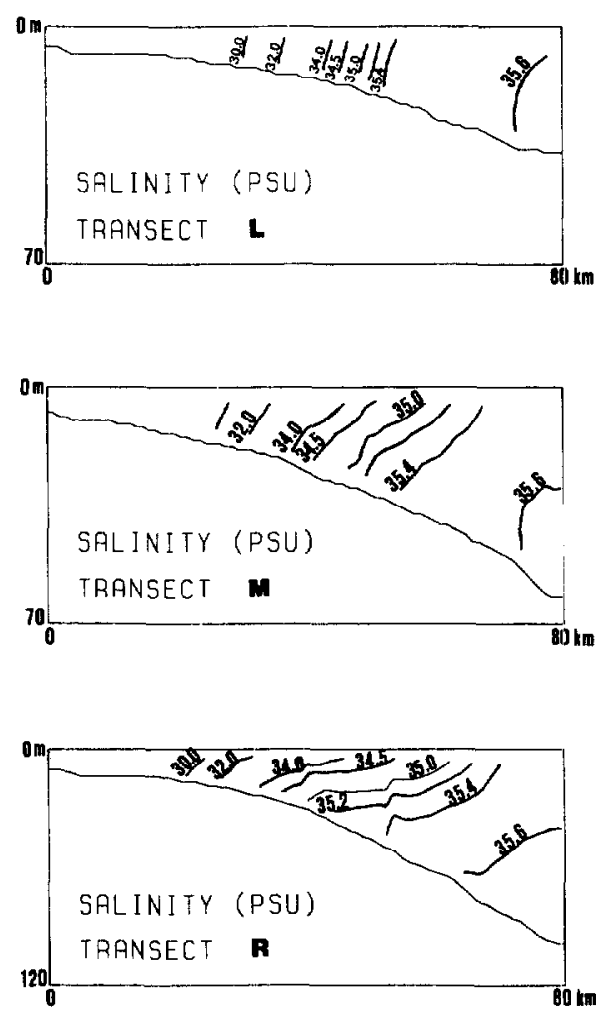

Fig. 8. Salinity (psu) profiles along different transects. For the position of the transects see Fig. (4).

salinity, i.e. a thermal front extending in the eastwest direction along the isobaths as in the initial data (Fig. 9a) and a uniform temperature gradient in the northern half when discharge of freshwater took place (Fig. 9b). The temperature varied in both cases between $\sim 28$ and $\sim 31^{\circ} \mathrm{C}$.

The intensity of tidal currents in the Colorado Delta did not change markedly from a situation with no river runoff (Carbajal, 1993) to the case in which a discharge of freshwater was considered (Fig. 13). However, the presence of freshwater was clearly manifested in the residual current. Fig. 10 depicts the Eulerian residual current in the surface layer after 15 and $100 M_{2}$ periods of simulation. In the first case (Fig. 10a), the residual current was generally minimal in the shallow regions of the delta and the influence of the river discharge limited to the area around island Montague. In the northern half, two topographic induced gyres, one cyclonic and the 
other anticyclonic, were found. Although in this area the number of model layers varied from 1 to 3 , the water column was almost homogeneous everywhere. Since the vertical homogeneity was not altered significantly by the presence of freshwater (see Fig. 8), the residual current was only slightly modified after $100 M_{2}$ periods (Fig. 10b). This small residual current explains the slow southwards expansion of the ROFI. After $15 M_{2}$ periods (Fig. 10a), the southern part had not yet been influenced by the input of freshwater. An anticyclonic and topographically induced residual current around the Wagner basin dominated in this region. This can be explained as follows; when the tidal flow leaves the Wagner
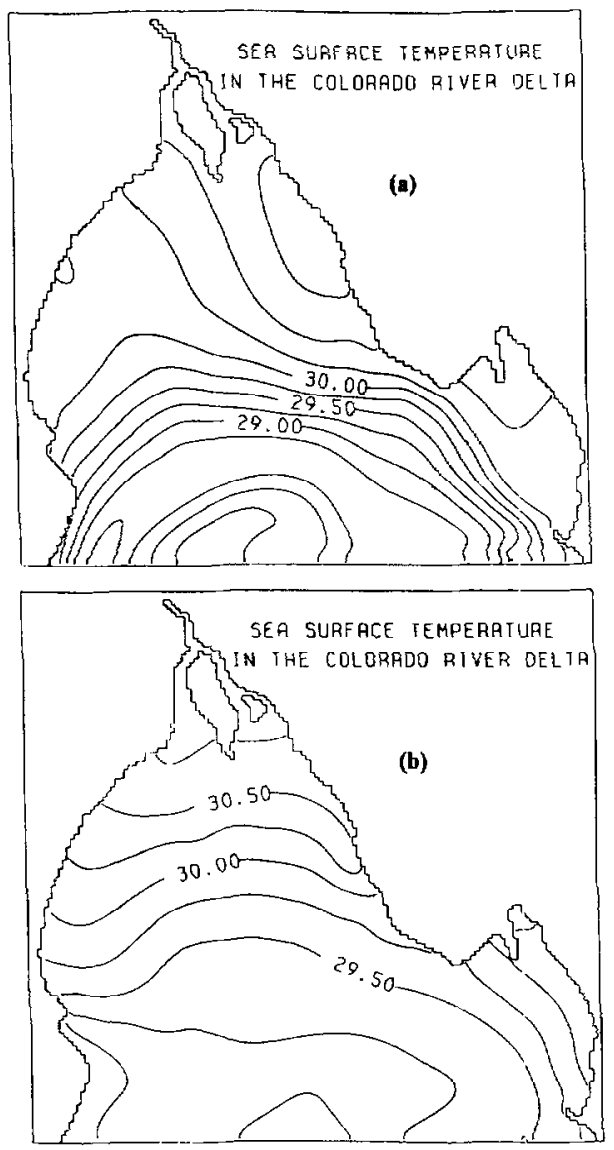

Fig. 9. Sea surface Temperature in ${ }^{\circ} \mathrm{C}$. (a) Temperature of actual conditions. (b) Temperature distribution after $100 M_{2}$ periods with the consideration of a constant discharge of freshwater of $2000 \mathrm{~m}^{3} / \mathrm{s}$.
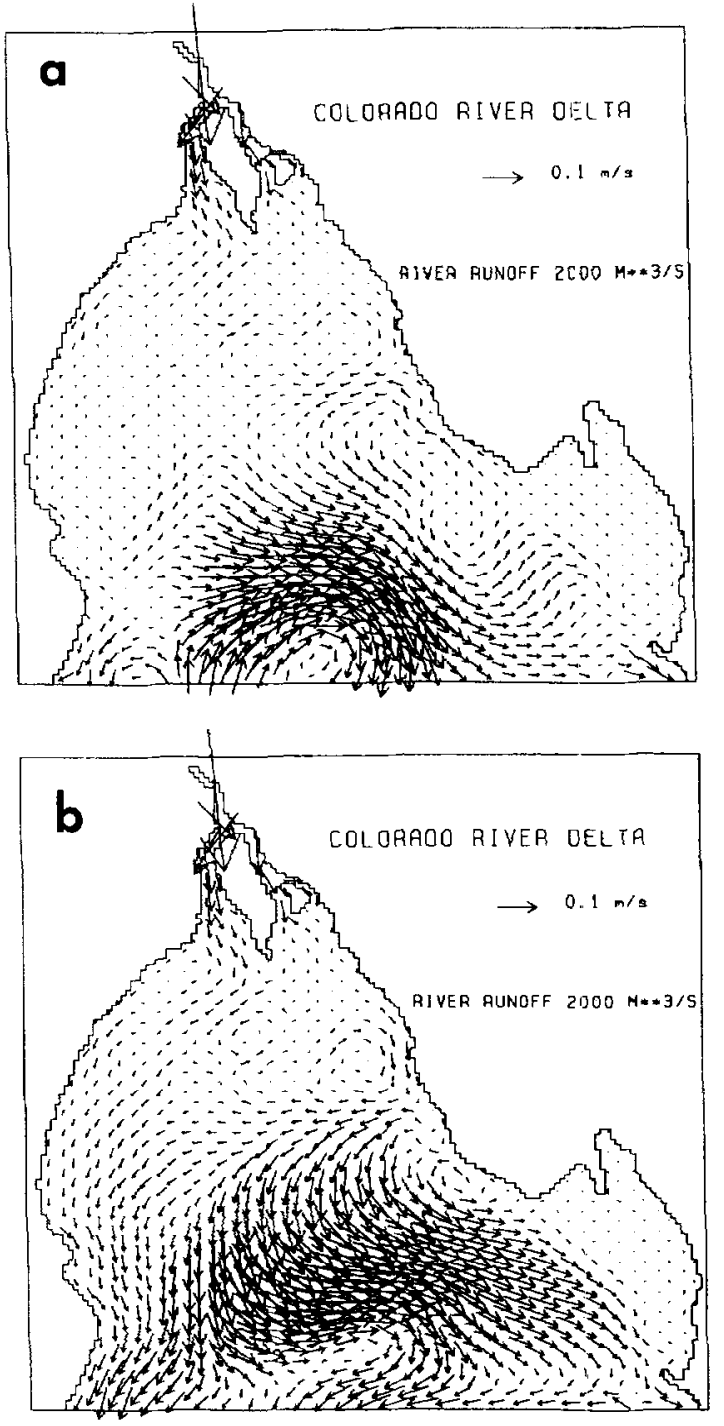

Fig. 10. Residual current $(\mathrm{m} / \mathrm{s})$ in the surface layer $(0-10 \mathrm{~m})$. (a) After 15 and (b) after $100 M_{2}$ periods.

basin northwards, the change from deep to shallow water induces anticyclonic vorticity which is reflected in a turning to the east. When the flow is southwards, cyclonic vorticity is produced, i.e again resulting in a turning to the east. A clockwise circulation results in a tidal cycle. In contrast to the northern half of the delta, this pattern underwent a severe modification with the influence of freshwater. In Fig. 10b, the residual flow increased markedly 

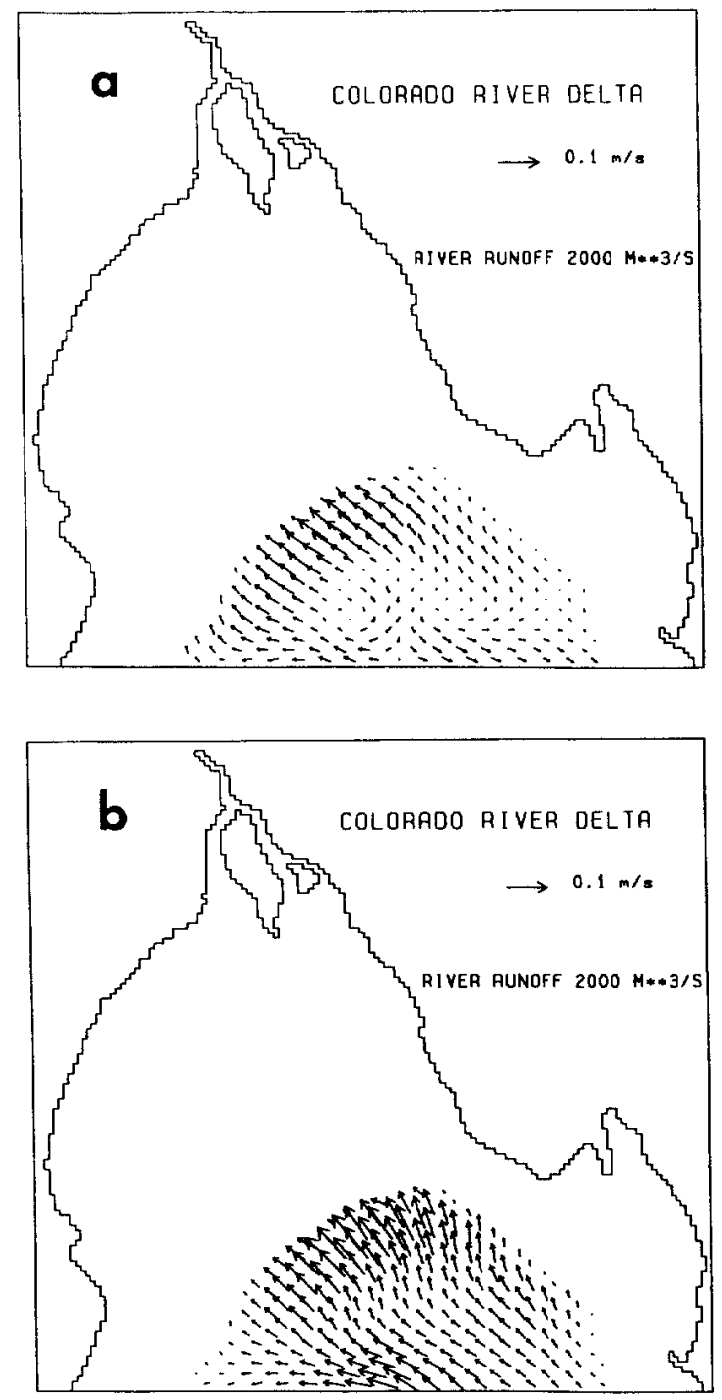

Fig. 11. Residual current $(\mathrm{m} / \mathrm{s})$ in the fifth layer $(50-100 \mathrm{~m})$. (a) After 15 and (b) after $100 M_{2}$ periods.

becoming dominantly southwards. Along the western and eastern sides, coastal jets developed and around the Wagner basin there was still the tendency to anticyclonic circulation. Observe that although the residual current increased slightly in the northern half, the flow pattern did not change. In the Adair bay the residual flow is small. Other important aspects that need to be mentioned, are that the volume of water of the river discharge flowed principally on the western side of the island Montague and that the

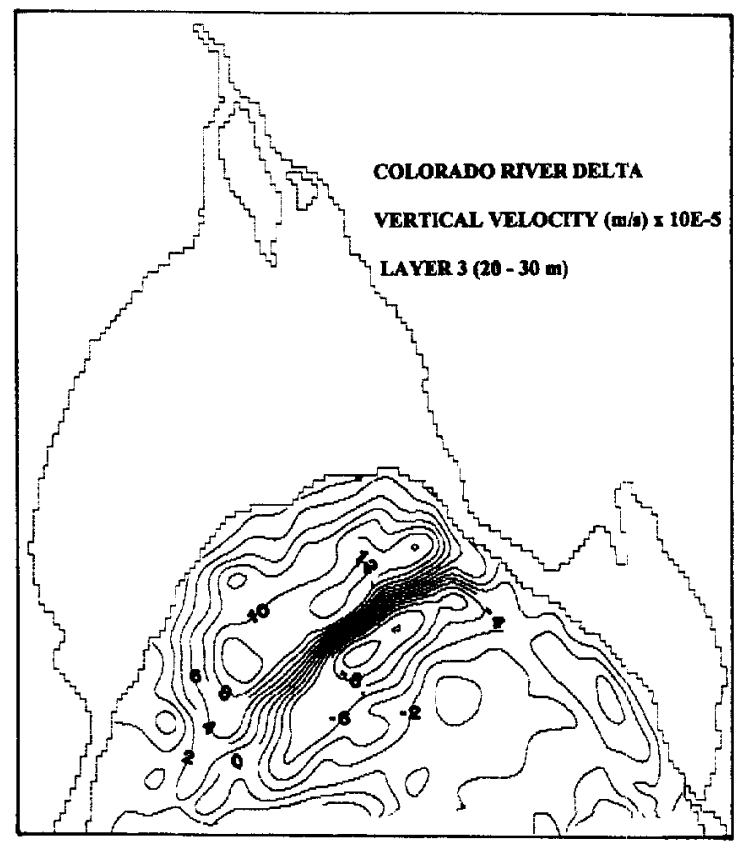

Fig. 12. Vertical velocity $\left(\mathrm{m} / \mathrm{s} \times 10^{-5}\right)$ in the third layer $(20-30$ m).

generally southward flow observed in the upper layer should have been compensated for by a northward flow in the bottom layer. Indeed, it occured princi-

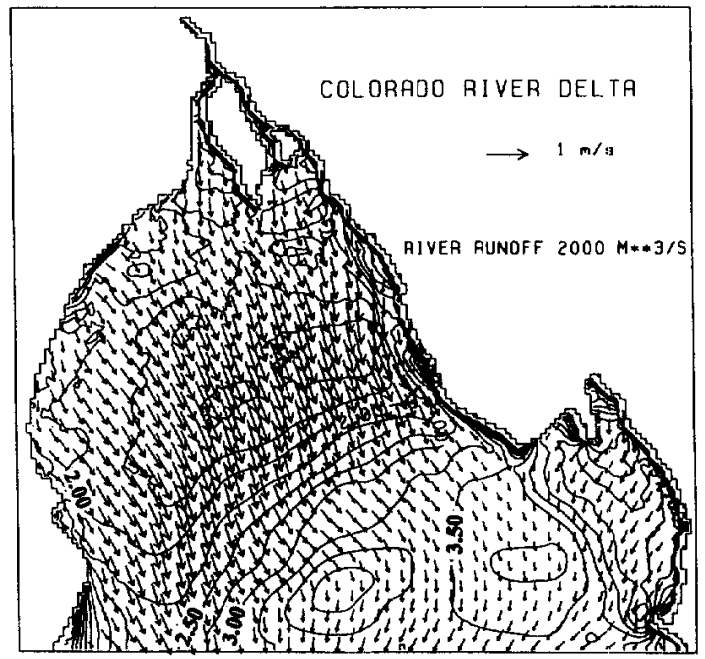

Fig. 13. Tidal currents at the time of maximum southwards flow and isolines of the parameter $\log \left(h / u^{3}\right)$. Velocities obtained after $100 M_{2}$ periods of simulation. 


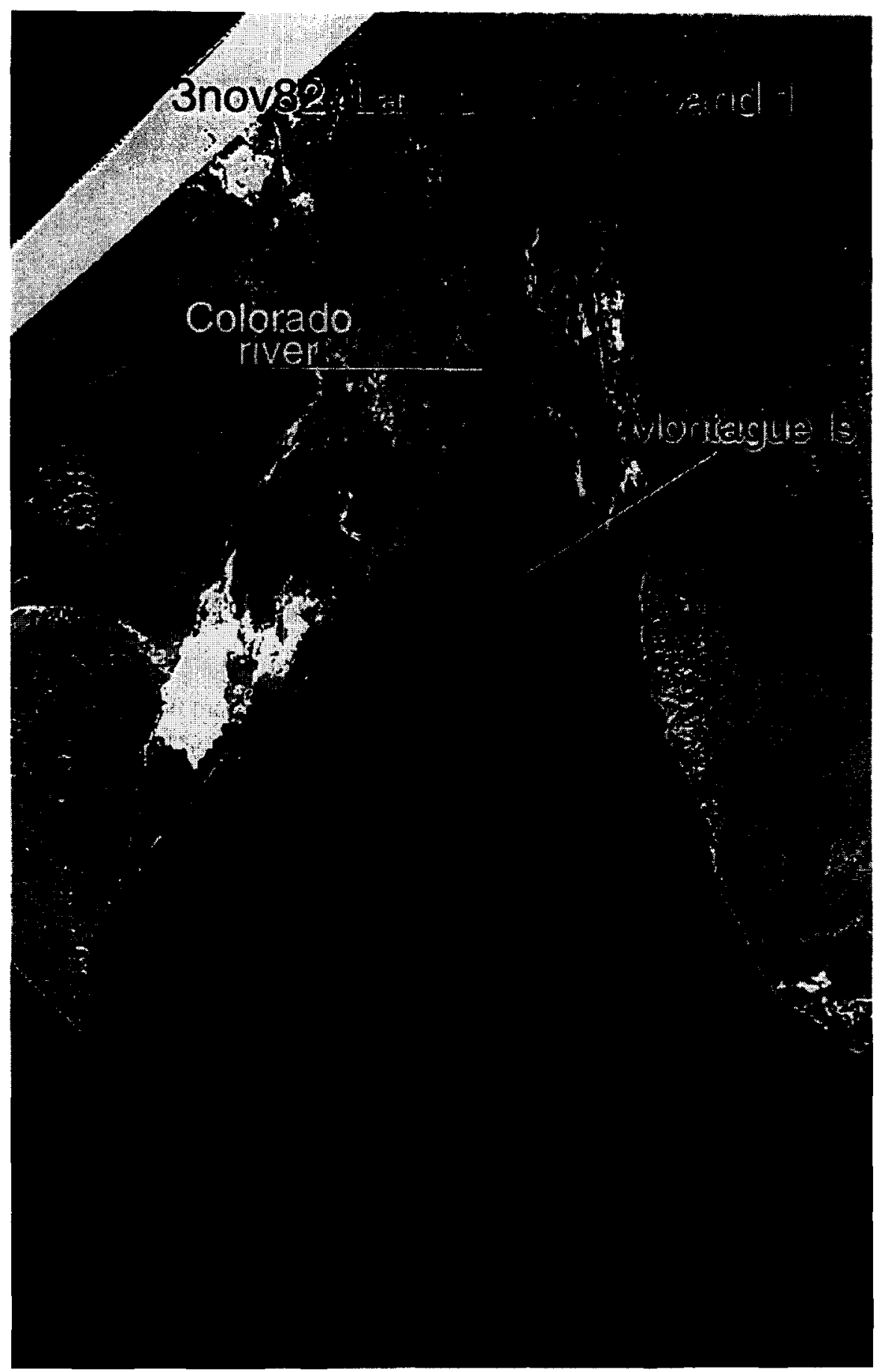

Fig. 14. LANDSAT MSS band 1 image of the Colorado Delta obtained on 3th November of 1982, two days after full moon. High reflectivity areas (bright zones) represent resuspended sediment over the shallow shelf. 


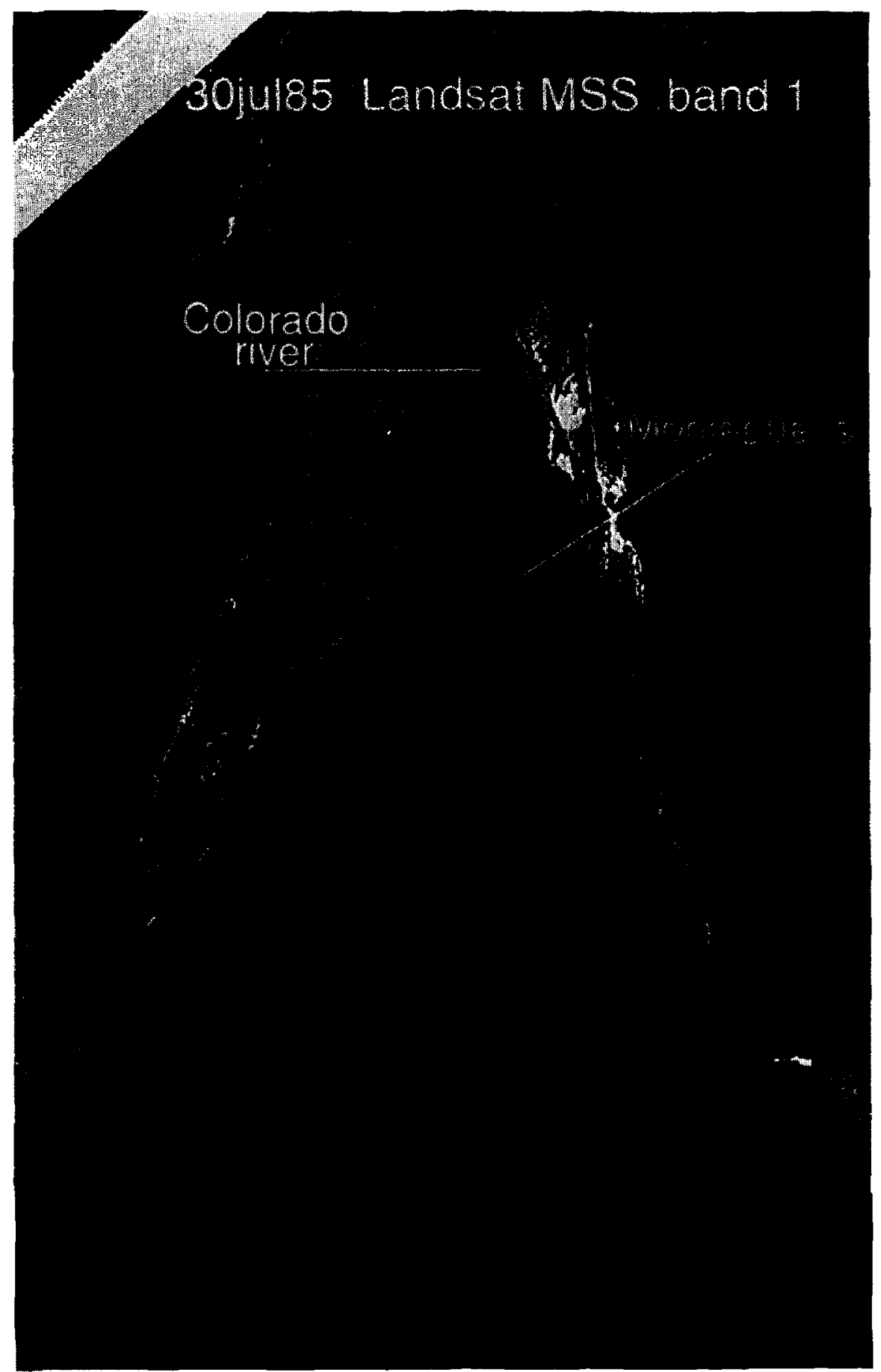

Fig. 15. LANDSAT MSS band 1 image of the Colorado Delta obtained on 30th July of 1985, one day and a half before full moon. 


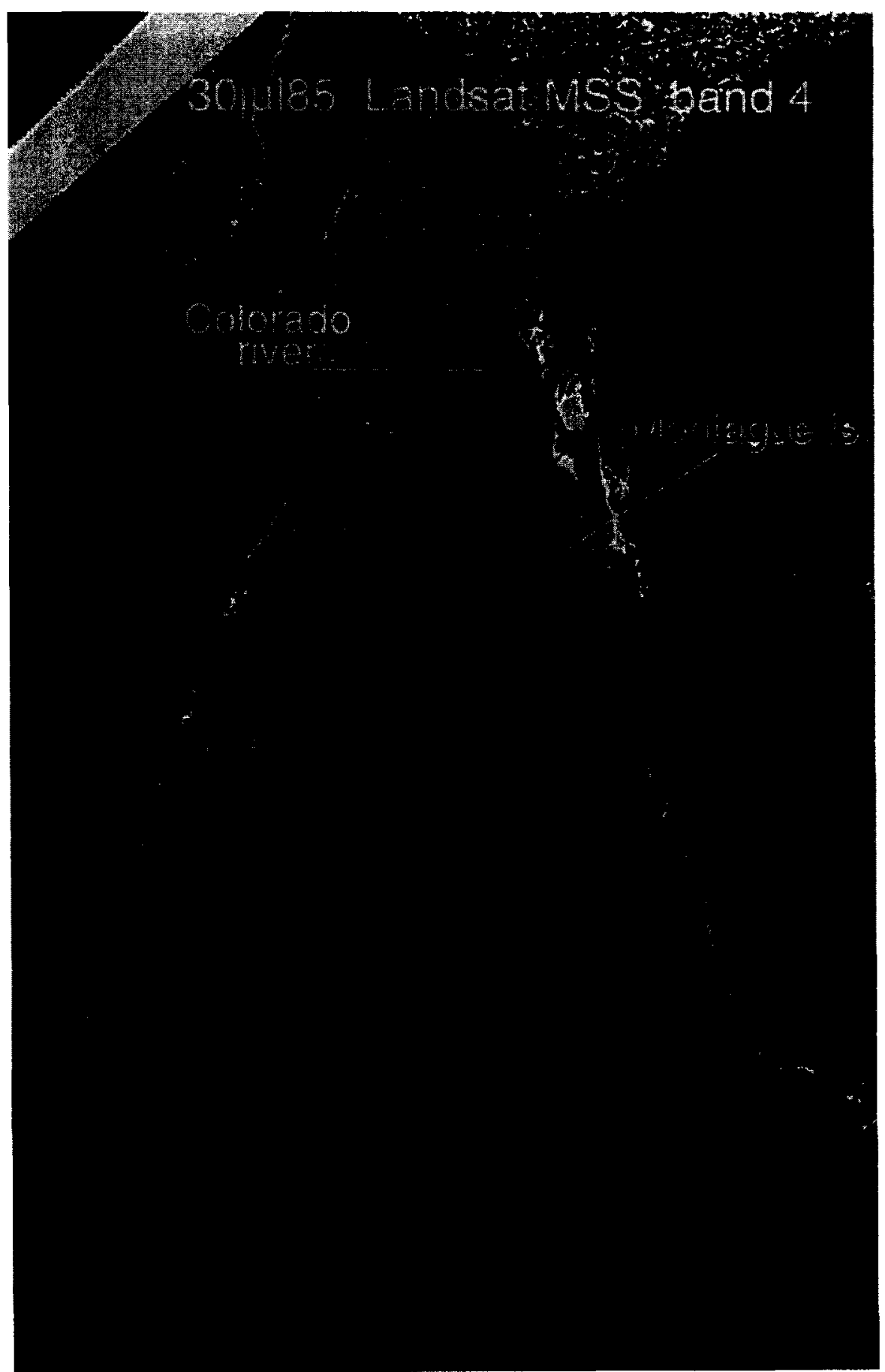

Fig. 16. LANDSAT MSS band 4 image of the Colorado Delta obtained on 30th July of 1985, one and a half day before full moon. Dark zones indicate the presence of water. 
pally below $50 \mathrm{~m}$. Fig. 11 displays the Eulerian residual current in the fifth layer $(50-100 \mathrm{~m})$. After $15 M_{2}$ periods (Fig. 11a), i.e. with no influence of freshwater, there was a northward flow, but it was largely the result of recirculation around the Wagner basin. In contrast, after $100 M_{2}$ periods the flow was decisively northwards. To summarize, the input of freshwater modified the residual flow pattern so that a strong water exchange with the northern part of the Gulf of California should have been possible through the Wagner basin. Furthermore, by observing the strong non-divergent flow pattern shown in Fig. 10b, an area of upwelling north of the Wagner basin is expected. Indeed, this can be seen in Fig. 12 where the vertical velocity in the third layer is depicted. Observe that north of the Wagner basin there is an area of upwelling with maximum vertical velocity values of $1.2 \times 10^{-4} \mathrm{~m} / \mathrm{s}$. This process might have played an important role in the productivity of the regions. Along the isobath of $40 \mathrm{~m}$ there is an intense horizontal gradient which separates the areas of upwelling and downwelling. This flow pattern indicates that water is partially recirculated in this region.

Another impressive manifestation of semidiurnal tides in the Colorado Delta was the amplitude of tidal currents. In Fig. 13, velocities associated with the $M_{2}$ tide at the time of maximum southwards flow are shown. A band of strong flow extended across the delta. In the middle of the basin velocities of about $0.8 \mathrm{~m} / \mathrm{s}$ were calculated. The effect of the Wagner basin was clearly manifested in a deflection of the flow and in the reduction of the velocities. In the Adair Bay velocities reached values of about $0.35 \mathrm{~m} / \mathrm{s}$. It will be shown in the next section that large phase gradients in the flow occured on both sides of the island Montague. The intensity and structure of tidal currents and the shallowness of the northern half of the Colorado Delta suggest the formation of fronts between vertically mixed and thermally stratified waters. In general, there is a competition between tidal and wind stirring mechanisms and the stratifying effects of heat and freshwater inputs. Simpson and Hunter (1974) gave a criterion by which the position of fronts resulting from tidal stirring can be estimated. Considerations of inputs of potential energy and dissipation of tidal energy lead to the important parameter $h / u^{3}$, where $h$ is the depth and $u$ is the tidal current amplitude. They found that fronts appear at contours of $\log \left(h / u^{3}\right) \sim(1.75-2.0)$ in the Irish Sea. In the German Bight fronts are located at values of $\log \left(h / u^{3}\right)$ $\sim$ (1.7-2.1) (Czitrom et al., 1988). This parameter was also calculated for the Colorado Delta and is shown in Fig. 13. Major changes in the amplitude of tidal currents took place between the contours of $\log \left(h / u^{3}\right)=2.5$ and 3.0. These results seem to be corroborated by satellite pictures. In Fig. 14 a LANDSAT MSS (band 1) image of the Colorado Delta obtained on 3th November of 1982 is shown. This image, taken two days after full moon i.e. almost at spring tides, exposed an homogeneous zone of high concentration of suspended sediment (clear areas) extending from coast to coast which substantially agreed with the calculated areas of intense tidal flow. The front is situated between the above mentioned values of 2.5 and 3.0 of the $\log \left(h / u^{3}\right)$ parameter. Areas with a smaller concentration of sediment around the Wagner basin could also be distinguished. However, this comparison is not completely valid since the corresponding LANDSAT MSS band 4 image did not show signs of freshwater input at this time. Fortunately there were images taken at times when significant discharge of freshwater occured. An example was the image obtained on 30th July of 1985 , one and a half day before full moon, i.e. almost at spring tides. It is displayed in Fig. 15. Its corresponding image in band 4 (Fig. 16) exhibited areas flooded with freshwater north of island Montague as well as the course of the Colorado River which could be distinguished clearly (see also Fig. 3 for the total annual river discharge). The freshwaler input seems to have influenced the concentration of suspended matter, since the pattern depicted in Fig. 15 differed from that shown in Fig. 14. The areas of high concentration of suspended matter are limited to the north and west coasts. However, an explanation for this difference could be that the pattern of Fig. 14 has experienced three and a half more days of spring tide conditions. The tidal ranges at these two dates were $\sim 5.8 \mathrm{~m}$ on 3th November of 1982 and of $\sim 4.1 \mathrm{~m}$ on 30th July of 1985. Another outstanding feature in Fig. 15 is the alternate fingers of major and minor concentrations of suspended sediment. This subject is discussed in further detail in the following section. 


\section{Discussion}

The results of our numerical calculations have been presented and are corroborated by satellite images. After $100 M_{2}$ periods of simulation, the Colorado ROFI reached a stationary state. Hydrographically, the region of freshwater influence is manifested principally northward of the Wagner basin. On initial approximation, this area with large salinity gradients, situated north of the isoline of $35 \mathrm{psu}$ (see Fig. 6b), defines a ROFI of $A \approx 80 \mathrm{~km} \times 100 \mathrm{~km}$. Based on this result and on observed physical quantities, the inputs of potential energy due to solar heating $B_{\mathrm{h}}=\alpha g Q / c_{p}$ and that associated with the river discharge $B_{\mathrm{r}}=R \Delta \rho g / A$ can be roughly estimated. $R=2000 \mathrm{~m}^{3} / \mathrm{s}$ is the river discharge, $Q=$ $100 \mathrm{~W} \mathrm{~m}^{-2}$ is the rate of heat input at the surface, $\Delta \rho=26 \mathrm{~kg} \mathrm{~m}^{-3}$ is the difference in density between freshwater and seawater, $c_{\mathrm{p}}$ is the specific heat at constant pressure and $\alpha$ is the thermal expansion coefficient. The calculation shows that $B_{\mathrm{h}} / B_{\mathrm{r}} \approx 1$. Since the parameters used in this simulation represent a season of maximum river discharge, this outcome reveals that the input of potential energy due to solar heating has probably been the most significant.

One of the main differences between the simulated Colorado ROFI and the prototypical ROFI is

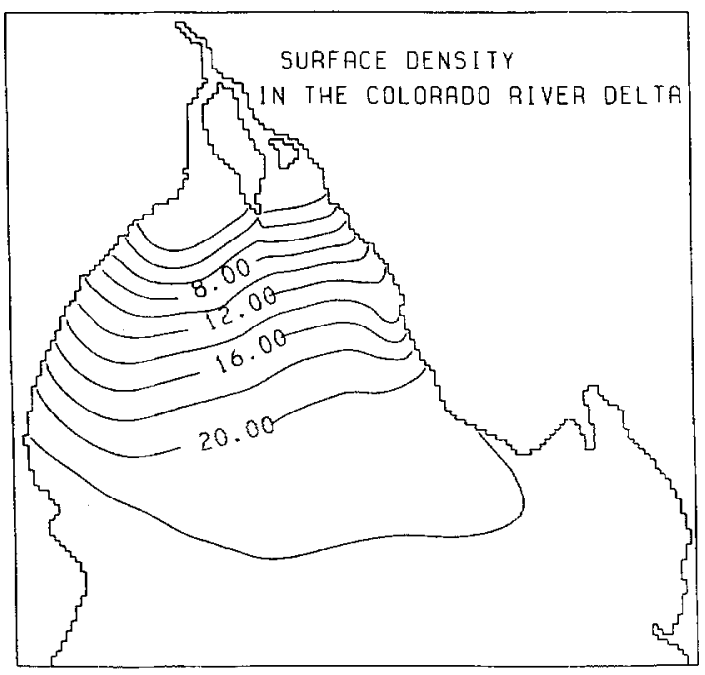

Fig. 17. Horizontal distribution of the density $\sigma_{S, I, P}$.

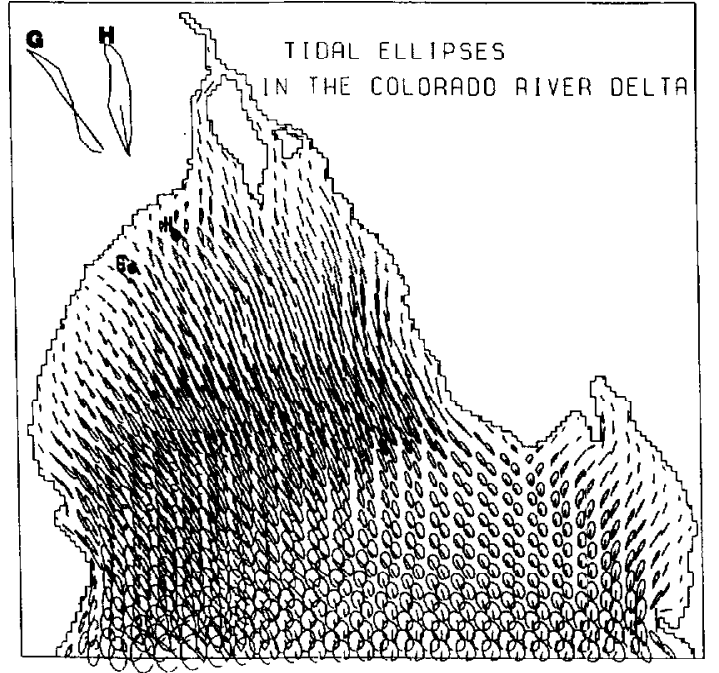

Fig. 18. Ellipses traced by the $M_{2}$ tide. The position of the two enlarged ellipses is indicated by the points $G$ and $H$.

that, at least in the northern half, the Colorado does not appear to create a current in the upper part of the water column. Intense tidal stirring inhibits stratification in that region. Following Simpson et al. (1994), it can be shown that the condition for estuarine stratification in a process of competition between estuarine bouyancy input and tidal stirring is given by

$$
\frac{1}{\rho} \frac{\partial \rho}{\partial x}>2.64 \times 10^{-4}\left(\frac{u}{h}\right)^{2}
$$

based on the resulting density distribution shown in Fig. 17, as well as from the bathymetry of the region (see Fig. 4), and using calculated velocity values (see Fig. 13) it can be proved that the Eq. (2) is hardly satisfied in the northern half of the Colorado River Delta. According to this simulation where only the $M_{2}$ tide was considered, the input of bouyancy due to the discharge of freshwater does not lead to stratification. However, the inclusion of the $S_{2}$ tide could modify this picture at times of destructive interference with the $M_{2}$ tide, i.e. at neap tides. There are reasons to assume that the Colorado ROFI has always behaved more as a 1-dimensional estuary than a prototypical ROFI, which would be characterized by an inertial turning of the discharged plume of 
freshwater and an intense coastal geostrophic current. Barotropic (Fig. 5) and baroclinic (Fig. 17) pressure gradients have a north-south direction which, according to the almost rectilinear tidal flow (Fig. 18), should be nearly balanced with bottom friction. Since the pattern and intensity of tidal currents is similar to barotropic calculations (Carbajal, 1993), it can be assumed that dissipation rates of tidal energy in both regimes (with and without river discharge) are of the same order. Therefore, the position of the $M_{2}$ amphidromic point was not influenced significantly by the process of freshwater reduction in this century. However, freshwater effects could be important in the vicinity of island Montague at neap tides. Nowadays, the tidal wave is dissipated to a large extent in this area. The presence of a river discharge would allow the propagation of the wave upstream which could slightly modify the dissipation rates.

In the southern half of the Colorado Delta, stratification associated with the input of freshwater seems to have been possible. Salinity transects given in Fig. 8 exhibit strong vertical changes which corroborate this statement. This could have led to a reduction of the vertical eddy viscosity. The intensification and the vertical structure of the residual current in this zone (Figs. 10 and 11) suggest a decoupling between surface (southward residual flow of low saline water) and bottom layers (northward residual flow of high saline water) which is typical for ROFI's. Therefore, one can argue that if there were a continuous river input of freshwater, then from the area around the Wagner basin, relative low saline water would propagate southwards much faster. Although the topographic effect of the Wagner basin markedly influences the residual flow pattern, it is in this region where there is a stronger tendency to a usual ROFI behaviour.

It has been previously stated that at present a typical annual cycle in this region can be described as follows: in summcr, salinity increases due to the high evaporative rates. Due to cooling in winter, this high saline water mass sinks and propagates towards the south where it plays an important role in a series of physical phenomena (see Fig. 1). These calculation showed that a seasonal high river discharge of freshwater would modify this process drastically and therefore would greatly influence the circulation specifically in the northern part of the Gulf of California.

The concentrations of suspended sediment observed specifically in Fig. 14 agree well with the calculated areas of intense tidal flow. These structures of suspended sediment seem to have a barotropic origin, since barotropic calculations (Carbajal, 1993) showing areas of strong tidal flow and those displayed in Fig. 13 are quite similar. Differences between the above mentioned barotropic calculations and our simulations have chiefly been made visible in Figs. 10 and 11 where estimated residual currents, with and without effects of river discharge, are exposed. The straight finger-like structures of alternate high and low concentration of suspended sediment (Fig. 15) appear to validate the 1-dimensionality of the northern half of the Colorado ROFI. In this area, the tidal flow is almost rectilinear, see Fig. 18 where the calculated tidal ellipses in the Colorado Delta are displayed. Although cyclonic rotation dominates, there are exceptions in the region to the southwest of island Montague where the velocity vector rotates anticyclonically, and even it can change the sense of rotation within a period (see the amplified ellipses). One might be inclined to think that these alternate concentration of suspended sediment are related to inputs of freshwater. However, in a recent work on tidal-induced regular bed form patterns, Hulscher (1995) showed that the presence of tidal induced sand waves and sand banks may be associated with free instabilities in a morphological system. This theory permits calculation of growth rates of bottom perturbations. For small values of ellipticity, i.e. almost rectilinear flow comparable to those observed in the upper half of the Colorado Delta, regular bed forms slightly rotated cyclonically with respect to the principal flow direction are predicted. Typical wave lengths would be of the order of 1 to $10 \mathrm{~km}$. This explanation seems to be more viable. This sediment plume mentioned by Baba et al. (1991), might be the source of the transport of sediments to deeper basins through the mechanisms of residual current, described in the last section. The sediment-plume outer boundary seems to coincide with the $40 \mathrm{~m}$ isobath: the boundary of the thermal front and the dividing line of upwelling and downwelling areas.

Other interesting phenomena taking place in the 

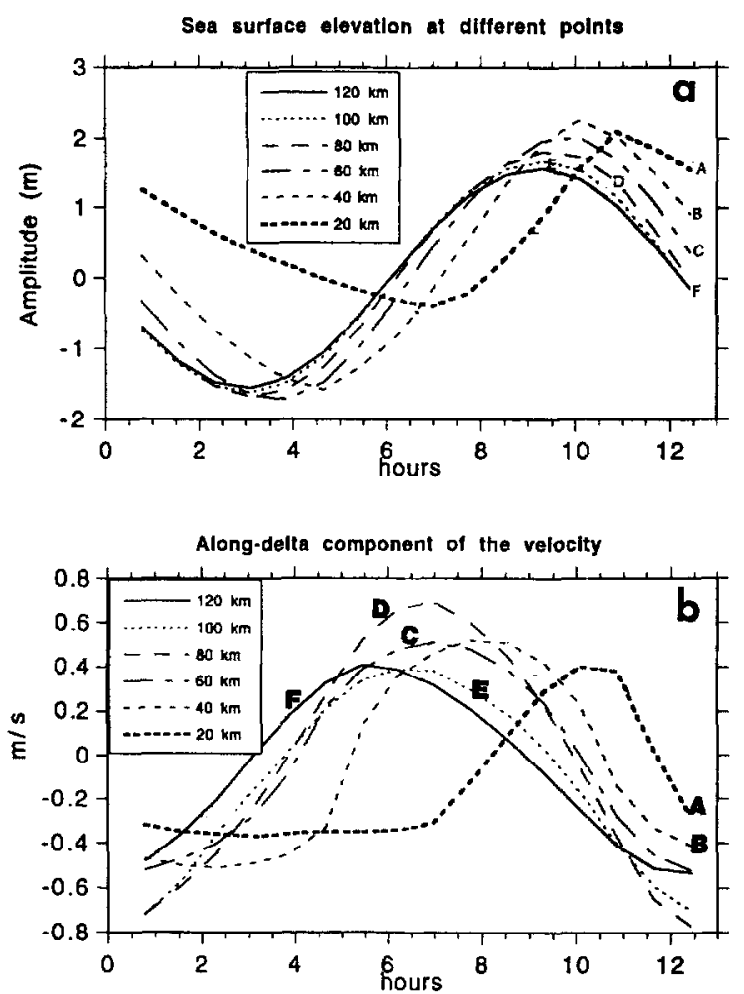

Fig. 19. Time series of the sea surface elevation (a) and of the amplitude of tidal currents (b) at several points along the delta. Their locations are indicated in Fig. (4) and their distances measured in $\mathrm{km}$ from the northern side are given in the legend.

Colorado Delta, are the large changes in phase and in amplitude of both sea surface elevation and current caused by the propagating $M_{2}$ tide (see Fig. 5). To analyse these aspects in more detail, time series of these two parameters are displayed in Fig. 19a, b for several points situated along a line extending from near the open boundary, up to the western side of island Montague. The position of these points (A, B, C, D, E, F) is given in Fig. 4. In (a), the sea surface elevation changed from a sinusoidal shape at the point $F$ near the open boundary to an asymmetric shape at point $\mathrm{A}$ on the western side of island Montague. The form of the curve was typical for flood dominant estuaries, i.e. a rapidly increasing amplitude and a slow reduction. Flood dominant estuaries are induced by strong friction (Speer et al., 1991). This increase in amplitude may be sharper in reality leading to the reported bore. In (b), time series of the velocity show a tendency from a sinusoidal at point $\mathrm{F}$ to a pulse-like shape at point $\mathrm{A}$. By continuity, the shape of the curve at point $A$ results from the time differentiation of the sea surface elevation.

\section{Conclusions}

Using a combination of measured data, physical criteria, numerical modelling and satellite imagery, we have obtained important basic information on hydrodynamic and hydrographic characteristics of the Colorado Delta. Two principal situations were investigated; one typifying present conditions (without river runoff) and a hypothetical representing conditions at the beginning of this century (with a large discharge of freshwater). Due to strong tidal mixing, the northern half of the delta behaves like a vertically well mixed 1-dimensional estuary in both regimes. In the southern half stratification associated with inputs of freshwater is possible. In this region, the Eulerian surface residual current is large and characterized by two coastal jets. Topographic effects are important in order to produce this pattern. In general there is a tendency to a weak ROFI-like behaviour in this area. Our calculations show that, as expected, the reduction of the discharge of freshwater in this century should have radically modified the hydrography and dynamics of the Colorado River Delta and of the northern part of the Gulf of California. The actual regime of salty water formed in summer, sinking in winter and propagating southwards is, to a large extent, surely man-made. It is difficult to say, however, with which intensity the absence of high saline water would modify vigorous mixing and advective processes taking place in the Ballenas Channel and around the Salsipuedes Sill.

There remain a series of phenomena to be investigated. The influence of wind was not included in this study. However, it can be anticipated that a northerly wind would probably intensify the coastal jet on the western side, and a southerly wind would favour a wider spreading of comparatively low saline water into the northern part of the Gulf of California. Another aspect is the observed finger-like structures 
which give some idea of the mobility of fine sediment. This process should be studied in detail. To gain a well-founded picture of the physical processes in this very energetic region, it is urgent and necessary to carry out observational campaigns.

\section{Acknowledgements}

The authors would like to thank Prof. J.H. Simpson and $G$. Allen for their valuable comments and suggestions. Thanks are also due to A. Visser for encouraging the undertaking of this study. This work was conducted within PROFILE, a European Union funded project under MAST programme. It was also supported by the School of Marine Sciences of the University of Baja California, Mexico. We are also indebted to the anonymous reviewers for their interesting hints.

\section{References}

Alvarez-Borrego, S. and Schwartzlose, R.A., 1979. Water masses of the Gulf of Califomia. Cienc. Mar., 6(1-2): 43-63.

Alvarez-Borrego, S., Flores-Baez, S. and Galindo-Bect, L.A., 1975. Hidrologia del alto Golfo de California II: Condiciones durante invierno, primavera y verano. Cienc. Mar., 2: 21-36.

Argote, M.L., Amador, A. and Morales, C., 1985. Variacion estacional de la estratificacion en la region norte del Golfo de California. In: J. Urnutia-Fucugauchi and J.F. Valdes-Galicia (Fditors), Memorias de la Reunion Anual 1985. Union Geofis. Mexicana, Mexico City, pp. 334-338.

Baba, J., Peterson, C.D. and Schrader, H.J., 1991. Fine-grained terrigenous sediment supply and dispersal in the Gulf of california during the last century. In: J.P. Dauphin and B.R.T. Simoneit (Editors), The Gulf and Peninsular Province of the Californias. Am. Assoc. Petrol. Geol. Mem., 47: 589-602.

Backhaus, J.O., 1985. A three-diemnsional model for the simulation of the shelf sea dynamics. Dtsch. Hydrograph. Z., 38: 165-187.

Baumert, H. and Radach, G., 1992. Hysteresis of turbulent kinetic energy in nonrotational tidal flows: A model study. J. Geophys. Res., 97(C3): 3669-3677.

Bray, N.A., 1988a. Thermohaline circulation in the Gulf of California. J. Geophys. Res., 93: 4993-5020.

Bray, N.A., 1988b. Water mass formation in the Gulf of California. J. Geophys. Res., 93: 9223-9240.
Carbajal, N., 1993. Modelling of the Circulation in the Gulf of California. Ph.D. Thesis, Inst. Oceanogr., Univ. Hamburg.

Castro, R., Lavin, M.F. and Ripa, P., 1994. Seasonal heat balance in the Gulf of California. J. Geophys. Res., 99(C2): 32493261.

Crean, P.B., Murty, T.S. and Stronach, J.A., 1988. Mathematical Modelling of Tides and Estuarine Circulation. In: Lecture Notes on Coastal and Estuarine Studies, 30. Springer, Berlin, $471 \mathrm{pp}$.

Czitrom, S.P.R., Budeus, G. and Krause, G., 1988. A tidal mixing front in an area influenced by land runoff. Continental Shelf Res., 8(3): 225-237.

Durazo, R., 1989. Frentes Termicos de Verano en el Alto Golfo de California. M.Sc. Thesis, CICESE, Ensenada, Mexico.

Hainbucher, D., Pohlmann, T. and Backhaus, J.O., 1987. Transport of conservative passive tracers in the North Sea: first results of a circulation and transport mode., Continental Shel Res., 7(10): 1161-1179.

Hill, A.E. and Simpson, J.H., 1989. On the interaction of thermal and haline fronts; The Islay front revisited. Estuarine Coastal Shelf Sci., 28: 495-505.

Hulscher, S.J.M.H., 1995. Tidal-induced large scale regular form patterns in a three-dimensional shallow water model. Rep., R 95-11. Inst. Mar. Atmos. Res. Utrecht Univ., The Netherlands.

Pohlmann, T., 1985. Simulation von Bewegungsvorgänge im Sudchinesischen Meer. Diplomarbeit im fach Ozeanographie an der Universität Hamburg.

Roden, G.I. and Emilsson, 1979. Physical Oceanography of the Gulf of California, Gulf of California Symposium, in Commemoration of the 50th Anniversary of the Universidad Nacional Autonoma de Mexico, Univ. Natl. Auton. Mexico.

Sedesol, 1993. Gaceta Ecologica, Vol. V(24): 2-7. Secretaria de Desarrollo Social Secretaria de Desarrollo Social, Mexico City.

Simpson, J.H. and Hunter, J.R., 1974. Fronts in the Irish Sea. Nature, 250: 404-406.

Simpson, J.H., Souza, A. and Lavin, M.F., 1994. Tidal mixing in the Gulf of California. In: K.J. Beven, P.C. Chattwin and J.H. Millbank (Editors), Mixing and Transport in the Environment. Wiley, Chichester.

Speer, P.E., Aubray, D.G. and Friedrichs, C.T., 1991. Nonlinear hydrodynamics of shallow tidal inlet/bay systems. In: B.B. Parker (Editor), Tidal Hydrodynamics. pp. 321-339.

Stronach, J.A., Backhaus, J.O. and Murty. T.S., 1993. An update on the numerical simulation of oceanographic processes in the waters between Vancouver Island and the mainland: the GF8 model. In: A.D. Ansell, R.N. Gibson and M. Barnes (Editors), Oceanogr. Mar. Biol. Annu. Rev., 31: 1-86.

Sykes, G., 1937. The Colorado Delta. Am. Gengr. Soc. Spec. Publ., 19. Kennikat Press, N.Y., 193 pp. 